\title{
Synthesis and Spectroscopic Analysis of the Nature of Coordination Modes of Ligands in Copper (II) and Cadmium (II) Complexes of Two N-Oxidobenzamide Derivatives
}

\author{
Saranya Sathiyavasan ${ }^{1}$, Maheswaran Sithambaresan ${ }^{2, ~ *, ~ P a r t h i b a n ~ G u n a s i n g h a m ², ~}$ \\ Ratnasothy Srikaran ${ }^{3}$ \\ ${ }^{1}$ Department of Human Biology, Faculty of Health-Care Sciences, Eastern University of Sri Lanka, Batticaloa, Sri Lanka \\ ${ }^{2}$ Department of Chemistry, Faculty of Science, Eastern University of Sri Lanka, Batticaloa, Sri Lanka \\ ${ }^{3}$ Department of Chemistry, Faculty of Science, University of Jaffna, Jaffna, Sri Lanka
}

\section{Email address:}

saranyasathiyavasan3@gmail.com (Saranya S.), msithambaresan@mail.com (Sithambaresan M.),parthig24@yahoo.com (Parthiban G.), ratnasothysrikaran@gmail.com (Srikaran R.)

${ }^{*}$ Corresponding author

\section{To cite this article:}

Saranya Sathiyavasan, Maheswaran Sithambaresan, Parthiban Gunasingham, Ratnasothy Srikaran. Synthesis and Spectroscopic Analysis of the Nature of Coordination modes of Ligands in Copper (11) and Cadmium (11) Complexes of Two N-Oxidobenzamide Derivatives. International Journal of Science, Technology and Society. Vol. 5, No. 5, 2017, pp. 179-181. doi: 10.11648/j.ijsts.20170505.16

Received: August 17, 2017; Accepted: August 25, 2017; Published: September 19, 2017

\begin{abstract}
N-Oxidobenzamide derivatives are powerful metal ion chelators. It is used as inhibitors of hypertension, tumor growth, inflammation, infectious agents, asthma, arthritis, Alzheimer's diseases and more. In this study, Copper (11) (SRC1 and SRC3) and Cadmium (11) (SRC2 and SRC4) complexes were synthesized from potassium N-Oxidobenzamide derivative ligands and they were characterized by using various techniques such as Infra-Red spectra, electronic spectra, melting point and conductivity measurements. The electronic spectral study and the melting point analysis revealed that the ligands are coordinated to the metal centre. IR and conductivity analyses confirm the coordination of hydroxamate ions to the metal centre as O, O-bidentate mode via the hydroxyl oxygen and the carbonyl oxygen atoms of the ligands. The proposed molecular structures for the newly formed complexes are also given.
\end{abstract}

Keywords: Hydroxamic Acids, N-Oxidobenzamide, Copper(11) Complex, Cadmium (11) Complex and Analytical Techniques

\section{Introduction}

Hydroxamic acids are naturally occurring or synthetic weak organic acids and produce hydroxamate ion [1,2]. They are preferably named as N-hydroxy amides'. They contain the oxime $(-\mathrm{N}-\mathrm{OH})$ and the carbonyl $(\mathrm{C}=\mathrm{O})$ groups and have the following structure as shown in Figure 1. The reasonable way of producing hydroxamic acid derivatives is the reaction of hydroxylamine with acid chlorides or esters [2].

Hydroxamic acids are hydrophilic organic compounds that can exhibit keto-iminol tautomerism, and both tautomers may exist as $\mathrm{Z}$ or E diastereomers [3]. The deprotonation could be either from the nitrogen or the oxygen, making them $\mathrm{N}$-acids or O-acids [4]. Depending on the $\mathrm{pH}$, two $(\mathrm{O}, \mathrm{O})$ binding modes of the ligands are accessible to metal ions [5]. The most important application of N-Oxidobenzamide is as good metal ion chelators [6]. This kind of compounds and their derivatives find many applications in chemistry and biology and have been the subject of many experimental investigations $[7,8]$.

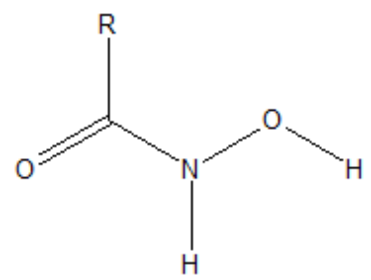

Figure 1. The structure of Hydroxamic acid. 


\section{Main Body}

\subsection{Materials \& Methodology.}

\subsubsection{Materials}

Coppersulphate pentahydrate $\left(\mathrm{CuSO}_{4} .5 \mathrm{H}_{2} \mathrm{O}\right)$ and Cadmium chloride $\left(\mathrm{CdCl}_{2}\right)$ (all are $\mathrm{AR}$ grade) were used without further purification. Methanol (GPR) was used as solvent. Ligands used are (SRL1 and SRL2) are shown in Figure 2.

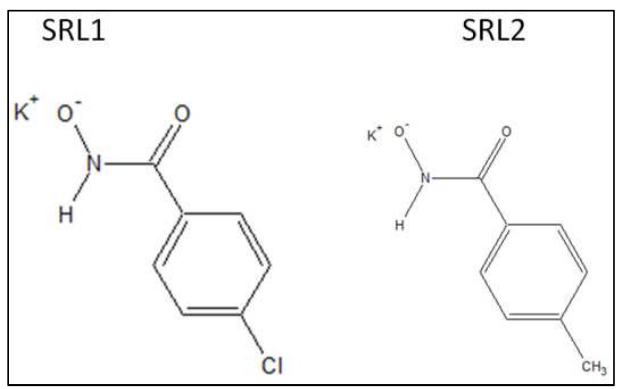

Figure 2. The structure of SRL1 and SRL2.

\subsubsection{Synthesis of the Complexes}

The metal salt and ligands (SRL1 and SRL2) were mixed in 1:2 ratio and the solution was refluxed to synthesized the Copper complexes (SRC1 and SRC3) and Cadmium complexes (SRC2 and SRC4) [9].

\subsection{Results \& Discussion}

The conductivity measurements were made in DMF solution and all complexes are found to be non-electrolytes. This confirms that, there are no anions present outside the coordination sphere of the complexes. The conductivity of the complexes and the melting point of the ligands and their complexes are shown in Table 1. The different and higher values of the melting points confirm the formation of the complexes. This was further confirmed by Thin Layer Chromatography (TLC).

Table 1. The conductivity, Melting point and Electronic spectra range of the ligands SRL1 and SRL2 and complexes SRC1, SRC2, SRC3 and SRC4.

\begin{tabular}{llllll}
\hline Analytical measurements & SRL1 & SRL2 & SRC1 & SRC2 & SRC3 \\
\hline Conductivity $(\mu \mathrm{s})$ & & & 1.20 & 2.10 & 1.90 \\
Melting point $\left({ }^{\circ} \mathrm{C}\right)$ & 120 & 110 & 180 & $>250$ & $>250$ \\
Electronic spectral data $(\mathrm{nm})\left(\mathrm{n} \rightarrow \pi^{*} / \pi \rightarrow \pi^{*}\right)$ & $260 \rightarrow 300$ & $260 \rightarrow 300$ & $260 \rightarrow 300$ & $260 \rightarrow 300$ & $260 \rightarrow 300$ \\
\hline
\end{tabular}

\subsubsection{Electronic Spectral Studies}

The significant electronic absorption bands in the spectra of the potassium hydroxamate derivative ligands and all the complexes were recorded in DMF solution. The potassium hydroxamate derivative and its $\mathrm{Cu}^{2+}$ and $\mathrm{Cd}^{2+}$ complexes have only a single broad band in electronic spectra centered at 260-300 $\mathrm{nm}$ region. This bands are due to $\pi \rightarrow \pi^{*}$ and $\mathrm{n} \rightarrow \pi^{*}$ transitions. These two electronic transitions are overlapped to give a broad absorbance. Shifting of peaks were observed in the spectra of complexes from that of ligands suggests that coordination of the ligands possibly occurred to the metal centre. Unfortunately, no appreciable absorption was observed above $800 \mathrm{~nm}$ in DMF solution indicating the presence of $\mathrm{d}-\mathrm{d}$ transitions in the complexes.

\subsubsection{Infrared Spectral Studies}

The IR spectrum of the ligands SRL1 and SRL2 and its complexes SRC1, SRC2, SRC3 and SRC4 showed some characteristic stretching bands at $3200-3300 \mathrm{~cm}^{-1}$ for $\mathrm{V}(\mathrm{N}$ $\mathrm{H})$, at $1610 \mathrm{~cm}^{-1}$ for $\mathrm{V}(\mathrm{C}=\mathrm{O})$, at $1432 \mathrm{~cm}^{-1}$ for $\mathrm{V}(\mathrm{C}-\mathrm{N})$, and at $908 \mathrm{~cm}^{-1}$ for $\mathrm{V}(\mathrm{N}-\mathrm{O})$ assigned to the functional groups present in the ligands and its complexes [10].

IR spectroscopic assignments for the ligand SRL1 and its $\mathrm{Cu}^{2+}$ and $\mathrm{Cd}^{2+}$ complexes and ligand SRL2 and its $\mathrm{Cu}^{2+}$ and $\mathrm{Cd}^{2+}$ complexes are shown in Table 2 .
Table 2. Infrared spectroscopic assignments $\left(\mathrm{cm}^{-1}\right)$ for the SRL2 and its $\mathrm{Cu} \mathrm{u}^{2+}$ and $\mathrm{Cd}^{2+}$ complexes.

\begin{tabular}{lllll}
\hline Compound & $\begin{array}{l}\mathbf{V}(-\mathbf{N}-\mathbf{H}) \\
\mathbf{c m}^{-\mathbf{1}}\end{array}$ & $\begin{array}{l}\mathbf{V}(\mathbf{C}=\mathbf{O}) \\
\mathbf{c m}^{-1}\end{array}$ & $\begin{array}{l}\mathbf{V}(\mathbf{C}-\mathbf{N}) \\
\mathbf{c m}^{-1}\end{array}$ & $\begin{array}{l}\mathbf{V}(\mathbf{N}-\mathbf{O}) \\
\mathbf{c m}^{-1}\end{array}$ \\
\hline SRL1 & 3264 & 1653 & 1432 & 908 \\
SRC1 & 3264 & 1643 & 1438 & 903 \\
SRC2 & 3269 & 1640 & 1440 & 903 \\
SRL2 & 3240 & 1677 & 1442 & 849 \\
SRC3 & 3245 & 1643 & 1442 & 844 \\
SRC4 & 3240 & 1643 & 1442 & 844 \\
\hline
\end{tabular}

The IR spectra of the free ligands and its $\mathrm{Cu}^{2+}$ and $\mathrm{Cd}^{2+}$ complexes indicate that the strong and sharp bands from 3240 to $3269 \mathrm{~cm}^{-1}$ are almost consistent with an amide type $\mathrm{N}-\mathrm{H}$ stretching mode. The carbonyl oxygen of the ligand will serve as a donor center in the metal. The conductivity measurements also show that all the complexes are nonelectrolytes revealing the fact that the central ionic charge

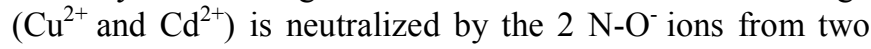
ligands rather than the enolic $\mathrm{O}$ atom of its tatoumer, thereby the electron is donated from the carbonyl oxygen group $(\mathrm{C}=\mathrm{O})$. This was further confirmed by the shift of sharp bands to lower frequencies in SRC1 and SRC2 from the ligand SRL1 and in both complexes SRC3 and SRC4 (1643 $\mathrm{cm}^{-1}$ ) reduced by $34 \mathrm{~cm}^{-1}$ from ligand SRL2. The $\mathrm{v}(\mathrm{C}-\mathrm{N})$ of the metal complexes, SRC1 and SRC2 is found to be increased slightly (1438 and $1440 \mathrm{~cm}^{-1}$ respectively) and in SRC3 and SRC4 is found to be consistent with that of the ligand SRL2 (1442 cm-1), suggesting the coordination via 
the keto oxygen atom. The reduction of $\mathrm{v}(\mathrm{N}-\mathrm{O})$ from the base value $908 \mathrm{~cm}^{-1}$ in the ligand SRL1 to $903 \mathrm{~cm}^{-1}$ in the complexes SRC1 and SRC2 and the weak intensity band at $849 \mathrm{~cm}^{-1}$ in SRL2 is shifted to lower frequency $844 \mathrm{~cm}^{-1}$ in both SRC3 and SRC4 indicates that the $\mathrm{N}-\mathrm{O}$ bond is weakened by the coordination via the $\mathrm{O}$ atom of $\mathrm{N}-\mathrm{O}$ moiety of the ligand.

According to the measurements and the spectroscopic assignments of these metal complexes, the possible and suggested tentative structures of the $\mathrm{Cu}$ (II) and $\mathrm{Cd}$ (II) complexes and coordination modes of the ligands are shown in Figure 3.

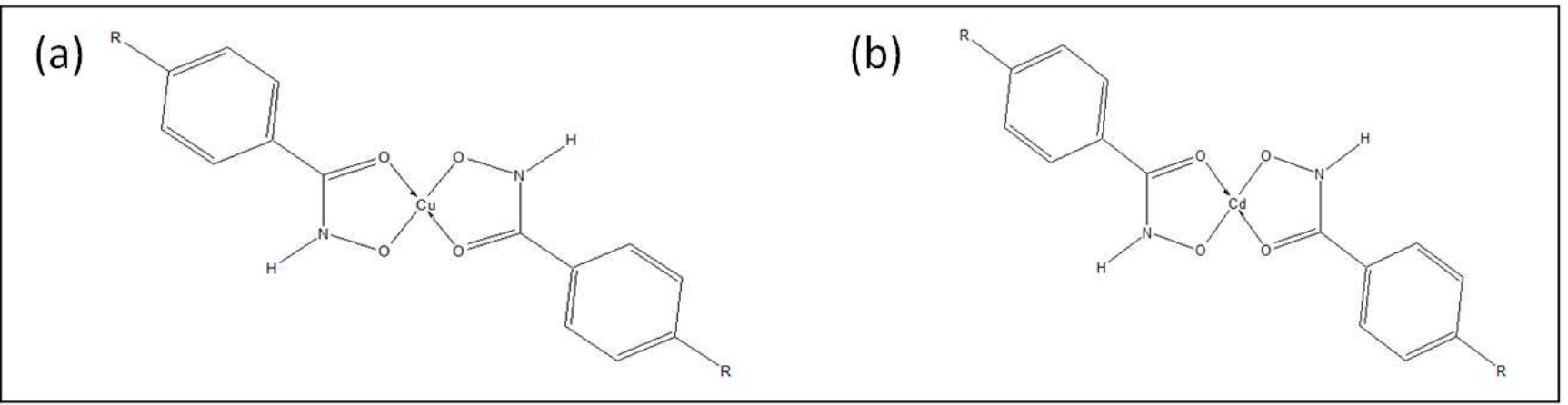

Figure 3. The tentative structure of $\mathrm{Cu}(\mathrm{II})-(\mathrm{a})$ and $\mathrm{Cd}(\mathrm{ll})-(\mathrm{b})$ metal complexes. $\mathrm{R}: \mathrm{Cl}, \mathrm{CH}_{3}$.

\section{Conclusion}

Novel complexes with derivatives of N-Oxidobenzamide ligands and $\mathrm{Cu}^{2+}$ and $\mathrm{Cd}^{2+}$ ions were successfully synthesized and they were partially characterized. The coordination behaviour of ligands towards the metals used were analyzed by IR and electronic spectroscopic techniques and also by melting point and conductivity measurements. The increase in the melting point in complexes from the ligand is concurrent with the formation of the complexes. The significant bands and their shifts observed in IR spectra of the complexes confirmed that the coordination via $\mathrm{O}$ atoms of $\mathrm{C}=\mathrm{O}$ and $\mathrm{N}-\mathrm{O}$ moieties to the metal centre. The conductivity data show that the complexes are nonelectrolytes in nature suggesting the $\mathrm{O}$, O-bidentate coordination of the ligands thereby confirm the absence of any ions outside the coordination sphere. The electronic studies were also found to be supportive to the above findings. The structural analysis of crystals of the complexes revealed that the two ligands are coordinated to a metal to give neutral metal complex in which each of the ligands is coordinated via two $\mathrm{O}$ atoms of the carbonyl oxygen and hydroxyl oxygen. The proposed structures of the complexes are also given.

\section{References}

[1] Rittakakkar, Theoretical studies on Hydroxamic Acids, Springer-Verlag Berlin Heideberg, (2013), P: 19-53.

[2] Naqeebullah, Yang Farina, KokMeng Chan, Lo Kong Mun Nor Fadilah Rajab and Theng Choon Ooi, Diorganotin (IV) Derivatives of N-Methyl p-Fluorobenzo-Hydroxamic Acid: Preparation, Spectral Characterization, X-ray Diffraction Studies and Antitumor Activity, Molecules (2013), 18, P: 8696-8711.

[3] Farkas, E., Csoka, H., Gama, S., Santos, M. A. Dihydroxamate based siderophore model, piperazine-1,4-bis-
(N-methyl-acetohydroxamic acid (PIPDMAHA), as a chelating agent of molybdenum(VI). Talanta (2002), 57, 935943.

[4] Munster, P. N.; Troso-Sandoval, T.; Rosen, N.; Rifkind, R.; Marks, P. A.; Richon, V. M. The histone deacetylase inhibitor suberoylanilide hydroxamic acid induces differentiation of human breast cancer cells. Cancer Res. (2001), 61, 84928497.

[5] Codd. R, Traversing the coordination chemistry and chemical biology of hydroxamic acid, Coord. Chem, Rev.(2008), 252, P: $1387-1408$.

[6] S. Sasi, M. Sithambaresan, MRP Kurup, HK Fun, Syntheses, EPR spectral studies and crystal structures of manganese (II) complexes of neutral N, N donor bidentate Schiff bases and azide/thiocyanate as coligand, Polyhedron (2010), 29, p: 2643-2650.

[7] Pavia, Lampman, Kriz, Vyvyan, Intoduction to Spectroscopy, Fourth Edition, Brooks/Cole Cengage Learning, (2007), P: 1589, 381-413.

[8] Jain, R.; Sundram, A.; Lopez, S.; Neckermann, G.; Wu, C.; Hackbarth, C.; Chen, D.; Wang, W.; Ryder, NS.; Weidmann, B.; et al. $\alpha$-Substituted hydroxamic acids as novel bacterial deformylase inhibitor-based antibacterial agents. Bioorg. Med. Chem. Lett. (2003), 13, 4223-4228.

[9] Petrosyan, V. S.; Yashina, N. S.; Ponomarev, S. V. Syntheses, Structures and biological activites of Organogermaniun and Organotin derivatives of hydroxamic acids. Met. Based Drugs (1998), 5, 237-244.

[10] Baul, T.; Masharing, C.; Ruisi, G.; Jirasko, R.; Holcapek, M.; De Vos, D.; Wolstenholme, D.; Linden, A. Self-assembly of extended Schiff base amino acetate keletons, 2-\{[(2Z)-(3hydroxy-1-Methyl-2-butenylidene)]amino Phenylpropio-nate and 2-\{[(E)-1-(2-hydroxy-aryl) alkylidene] amino $\}$ Phenylpropionate skeletons incorporating organotin(IV) moieties: Synthesis, spectroscopic characterization, crystal structures, and in vitro cytotoxic activity. J. Organomet. Chem. (2007), $692,4849-4862$. 